\title{
Evaluation of hygiene habits: cross-sectional study
}

\author{
Manuel António Campos ${ }^{1,2,3,4}$, Ana Cristina Sousa ${ }^{1}$, Paulo Varela $^{1}$, Armando Baptista $^{1}$
}

\begin{abstract}
Introduction: It is well known that adequate hygiene is important for health. Even though this topic has drawn the attention of the media, little or no scientific investigation has been done.

Methods: We performed a comparative questionnaire-based cross-sectional study in three groups: patients attending a dermatology outpatient clinic, patients attending an internal medicine consultation, and community members.

Results: We analyzed a total of 446 questionnaires (249 from dermatology patients, 98 from internal medicine patients, and 99 from the community group). The three groups did not differ statistically in sex and age $(p=0.070)$. The patients from the dermatology department had a higher education level. The number of weekly baths did not differ among the three groups ( $p=0.417$ ). Hair hygiene did not differ between the three groups. The dermatology and internal medicine groups washed their hands more frequently than the community group $(p=0.028)$.

Conclusion: Comparing our results to the limited data available, we find that the population surveyed has better hygiene habits than those previously reported. We believe that hygiene habits should be discussed during office visits.
\end{abstract}

Keywords: cross-sectional study, epidemiology, hygiene habits, dermatology

Received: 31 July 2016 | Returned for modification: 17 August 2016 | Accepted: 22 August 2016

\section{Introduction}

The skin is the body's largest and most visible organ. It reflects a person's general health and performs many important functions (1). It is well known that adequate hygiene is important for good health. Poor hygiene can be associated with individual or community health problems, especially infectious diseases. On the other hand, excessive hygiene can aggravate skin conditions such as atopic dermatitis (2). Although this topic has drawn media attention, little to no scientific investigation has been carried out on worldwide population hygiene habits, except for hand hygiene as part of the prevention of iatrogenic or hospital-acquired infections.

No study evaluating skin hygiene was found in PubMed and the only information retrieved was based on internet surveys of the general population. A French internet survey (3), with a sample population of 566 individuals, stated that $70 \%$ of women and $60 \%$ of men do not shower every day. An English internet survey (4), with a sample population of 2,021 women, stated that 4 out of 5 women admit they do not shower every day and 33\% said they could go for three days without washing their body. The most common reason given for showering so little was time constraints. Despite these results, $92 \%$ of the women stated that they understood the importance of a proper skin care regime.

In our dermatology practice we have patients from all kinds of social and economic levels with different hygiene habits. Dermatology patients are said to have better skin and body hygiene than patients from other departments, although no study has evaluated this premise. Common knowledge suggests that individuals that undergo regular medical follow-ups have better health/hygiene practices than individuals with no medical follow-up, even though there are no studies that support this hypothesis.

The primary objective of this study was to determine if there were differences in hygiene habits in three different groups of in- dividuals (dermatology patients vs internal medicine patients vs community members).

Secondary aims included: (1) Determine if there were differences in hygiene habits in each group (2) Describe hygiene habits in the different groups of individuals; and (3) Identify poor hygiene behaviors that should be addressed and discussed during future consultations.

\section{Methods}

\section{Construction and validation of the questionnaire}

A 20-item questionnaire was created using input from seven dermatologists. We applied the questionnaire experimentally to 100 patients and observed response rates. After repeating this procedure twice, the final version of the questionnaire was composed of 16 items divided into five dimensions: 1) Sociodemographics, 2) Body hygiene, 3) Hair hygiene, 4) Hand hygiene, and 5) Other aspects (see Table 1).

\section{Study design}

The study was a comparative questionnaire-based cross-sectional study of three groups of individuals: patients attending the dermatology outpatient clinic, patients attending internal medicine consultation, and community members. The study was approved by the local ethics committee.

\section{Subject selection}

Copies of the questionnaire were distributed to patients attending consultations at the Department of Dermatology of the Vila Nova de Gaia e Espinho Central Hospital (CHVNGE), at the CHVNGE Department of Internal Medicine, and to community members 
(shopping malls and community parks). Inclusion criteria included patients more than 18 years old and exclusion criteria included illiteracy and incomplete questionnaires. A cover letter described the purpose of the study and invited individuals to participate on a voluntary basis. Participation in this study was anonymous and no identifying data was collected. The study met the criteria of "Good Clinical Practice" and the principles of the Declaration of Helsinki as reflected in the approval by our institution's human research review committee.

Only questionnaires with $100 \%$ response rates were analyzed. This criterion was selected after all questionnaires were collected, but before data analysis.

The study began in November 2014 and ended in March 2015. Table 1 | Comparison between groups: results and questionnaire analysis.

\section{Statistical analysis}

SPSS version 22 (SPSS IBM, New York, U.S.A) was used to perform the statistical analysis of the data. Chi-square was used to study the association between groups. One-way ANOVA was used to compare means between groups. A significance level (alpha) of 0.05 was used.

\section{Results}

We analyzed a total of 446 questionnaires (249 from dermatology patients (55.8\% female and 44.2\% male), 98 from internal medicine patients $(67.3 \%$ female and $32.7 \%$ male) and 99 from the com-

\begin{tabular}{|c|c|c|c|c|c|c|}
\hline & & & $\begin{array}{l}\text { Dermatology } \\
\text { group }\end{array}$ & $\begin{array}{l}\text { Internal medicine } \\
\text { group }\end{array}$ & $\begin{array}{l}\text { Community } \\
\text { group }\end{array}$ & $\mathrm{p}$ \\
\hline & & Number (n) & 249 & 98 & 99 & \\
\hline \multirow{5}{*}{$\begin{array}{l}\text { Socio- } \\
\text { Demographics }\end{array}$} & Sex & $\begin{array}{l}\text { Female (\%) } \\
\text { Male (\%) }\end{array}$ & $\begin{array}{l}139(51.5) \\
110(62.5)\end{array}$ & $\begin{array}{l}66(24.4) \\
32(18.2)\end{array}$ & $\begin{array}{l}65(24.1) \\
34(19.3)\end{array}$ & $p=0.070$ \\
\hline & Age & Mean age (years) & $47.65( \pm 20.78)$ & $53.63( \pm 19.13)$ & $43.74( \pm 13.16)$ & $\begin{array}{l}p<0.001 \\
\text { (ANOVA) }\end{array}$ \\
\hline & Education & $\begin{array}{c}\text { Did not attend school } \\
\text { High school } \\
\text { University }\end{array}$ & $\begin{array}{c}7(100 \%) \\
197(51.3 \%) \\
45(81.8 \%) \\
\end{array}$ & $\begin{array}{c}0 \\
90(23.4 \%) \\
8(14.6 \%) \\
\end{array}$ & $\begin{array}{c}0 \\
97(25.3 \%) \\
2(3.6 \%) \\
\end{array}$ & \\
\hline & Work status & $\begin{array}{c}\text { Employed } \\
\text { Unemployed } \\
\text { Retired } \\
\text { Student } \\
\end{array}$ & $\begin{array}{l}97(46.2 \%) \\
31(47.0 \%) \\
81(65.3 \%) \\
40(87.0 \%)\end{array}$ & $\begin{array}{c}42(20.0 \%) \\
16(24.2 \%) \\
38(30.6 \%) \\
2(4.3 \%) \\
\end{array}$ & $\begin{array}{c}71(33.8 \%) \\
19(28.8 \%) \\
5(4.0 \%) \\
4(8.7 \%) \\
\end{array}$ & $p<0.001$ \\
\hline & Do you have any skin disease? & $\begin{array}{l}\text { No } \\
\text { Yes }\end{array}$ & $\begin{array}{l}114(39.0 \%) \\
135(87.7 \%) \\
\end{array}$ & $\begin{array}{c}94(32.2 \%) \\
4(2.6 \%) \\
\end{array}$ & $\begin{array}{c}84(28.8 \%) \\
15(9.7 \%) \\
\end{array}$ & $p<0.001$ \\
\hline \multirow{5}{*}{ Body Hygiene } & $\begin{array}{c}\text { How often do you take a bath } \\
\text { per week? }\end{array}$ & $\begin{array}{c}1-2 \\
3-4 \\
\text { Every day } \\
\text { More than once a day } \\
\end{array}$ & $\begin{array}{c}38(55.9 \%) \\
79(51.3 \%) \\
125(58.4 \%) \\
7(70.0 \%) \\
\end{array}$ & $\begin{array}{c}18(26.5 \%) \\
36(23.4 \%) \\
44(20.6 \%) \\
0 \\
\end{array}$ & $\begin{array}{c}12(17.6 \%) \\
39(25.3 \%) \\
45(21.0 \%) \\
3(30.0 \%) \\
\end{array}$ & $p=0.417$ \\
\hline & Reason for showering so little & $\begin{array}{l}\text { Yes } \\
\text { No }\end{array}$ & $\begin{array}{c}36(72.0 \%) \\
213(53.8 \%) \\
\end{array}$ & $\begin{array}{c}4(8.0 \%) \\
94(27.7 \%) \\
\end{array}$ & $\begin{array}{l}10(20.0 \%) \\
89(22.5 \%) \\
\end{array}$ & $p=0.021$ \\
\hline & When you bathe, you use: & $\begin{array}{c}\text { Soap } \\
\text { Bar soap ("lye soap") } \\
\text { Shower gel } \\
\text { Shampoo } \\
\text { Other } \\
\end{array}$ & $\begin{array}{c}55(47.4 \%) \\
25(46.3 \%) \\
158(62.0 \%) \\
10(50.0 \%) \\
1(100 \%) \\
\end{array}$ & $\begin{array}{c}32(27.6 \%) \\
20(37.0 \%) \\
38(14.9 \%) \\
8(40.0 \%) \\
0 \\
\end{array}$ & $\begin{array}{c}29(25.0 \%) \\
9(16.7 \%) \\
59(23.1 \%) \\
2(10.0 \%) \\
0 \\
\end{array}$ & $p=0.003$ \\
\hline & How do you bathe? & $\begin{array}{c}\text { Shower } \\
\text { Immersion }\end{array}$ & $\begin{array}{c}239(55.8 \%) \\
10(55.6 \%) \\
\end{array}$ & $\begin{array}{c}96(22.4 \%) \\
2(11.1 \%) \\
\end{array}$ & $\begin{array}{c}93(21.7 \%) \\
6(33.3 \%) \\
\end{array}$ & $p=0.358$ \\
\hline & \begin{tabular}{|c|}
$\begin{array}{c}\text { Have you reduced the number } \\
\text { of baths in the last } 2 \text { years? }\end{array}$ \\
\end{tabular} & $\begin{array}{l}\text { No } \\
\text { Yes }\end{array}$ & $\begin{array}{c}236(55.0 \%) \\
13(76.5 \%)\end{array}$ & $\begin{array}{c}98(22.8 \%) \\
0 \\
\end{array}$ & $\begin{array}{c}95(22.1 \%) \\
4(23.5 \%)\end{array}$ & $p=0.073$ \\
\hline \multirow[b]{3}{*}{ Hair Hygiene } & $\begin{array}{l}\text { How often do you wash your } \\
\text { hair per week? }\end{array}$ & $\begin{array}{c}1-2 \\
>3-4\end{array}$ & $\begin{array}{c}72(50.3 \%) \\
174(58.0 \%)\end{array}$ & $\begin{array}{l}38(26.6 \%) \\
60(20.0 \%)\end{array}$ & $\begin{array}{l}33(23.1 \%) \\
66(22.0 \%)\end{array}$ & $p=0.227$ \\
\hline & $\begin{array}{l}\text { Where do you wash } \\
\text { your head? }\end{array}$ & $\begin{array}{c}\text { At home } \\
\text { At hairdresser } \\
\text { At home and hairdresser }\end{array}$ & $\begin{array}{c}173(53.4 \%) \\
5(38.5 \%) \\
71(65.1 \%) \\
\end{array}$ & $\begin{array}{c}76(23.5 \%) \\
2(15.4 \%) \\
20(18.3 \%) \\
\end{array}$ & $\begin{array}{c}75(23.1 \%) \\
6(46.2 \%) \\
18(16.5 \%) \\
\end{array}$ & $p=0.060$ \\
\hline & $\begin{array}{c}\text { When you wash your hair, } \\
\text { you use: }\end{array}$ & $\begin{array}{l}\text { Over-the-counter Shampoo / } \\
\text { conditioner } \\
\text { Shampoo / conditioner from } \\
\text { pharmacy } \\
\text { Shampoo / conditioner from } \\
\text { hairdresser } \\
\text { Soap } \\
\text { Other }\end{array}$ & $\begin{array}{c}167(57.6 \%) \\
43(64.2 \%) \\
24(41.4 \%) \\
10(40.0 \%) \\
5(83.3 \%) \\
\end{array}$ & $\begin{array}{c}58(20.0 \%) \\
14(20.9 \%) \\
12(20.7 \%) \\
14(56.0 \%) \\
0 \\
\end{array}$ & $\begin{array}{c}65(22.4 \%) \\
10(14.9 \%) \\
22(37.9 \%) \\
1(4.0 \%) \\
1(16.7 \%) \\
\end{array}$ & $p<0.001$ \\
\hline \multirow[b]{2}{*}{ Hand Hygiene } & $\begin{array}{l}\text { How often do you wash your } \\
\text { hands per day? }\end{array}$ & $\begin{array}{l}1-2 \\
3-4 \\
>5\end{array}$ & $\begin{array}{c}12(54.5 \%) \\
54(50.0 \%) \\
183(57.9 \%) \\
\end{array}$ & $\begin{array}{c}6(27.3 \%) \\
18(16.7 \%) \\
74(23.4 \%) \\
\end{array}$ & $\begin{array}{c}4(18.2 \%) \\
36(33.3 \%) \\
59(18.7 \%)\end{array}$ & $p=0.028$ \\
\hline & $\begin{array}{l}\text { When you wash your hands } \\
\text { you use: }\end{array}$ & $\begin{array}{c}\text { Solid soap } \\
\text { Liquid soap } \\
\text { Bar soap (“lye soap”) } \\
\text { Shower gel } \\
\text { Water } \\
\text { Other } \\
\end{array}$ & $\begin{array}{c}70(63.3 \%) \\
129(58.9 \%) \\
35(44.9 \%) \\
9(60.0 \%) \\
5(21.7 \%) \\
1(100.0 \%) \\
\end{array}$ & $\begin{array}{c}20(18.2 \%) \\
40(18.3 \%) \\
32(41.0 \%) \\
2(13.3 \%) \\
4(17.4 \%) \\
0 \\
\end{array}$ & $\begin{array}{c}20(18.2 \%) \\
50(22.8 \%) \\
11(14.1 \%) \\
4(26.7 \%) \\
14(60.9 \%) \\
0 \\
\end{array}$ & $p<0.001$ \\
\hline Other & Do you use beauty products? & $\begin{array}{l}\text { No } \\
\text { Yes }\end{array}$ & $\begin{array}{c}99(54.1 \%) \\
150(57.0 \%)\end{array}$ & $\begin{array}{l}46(25.1 \%) \\
52(19.8 \%)\end{array}$ & $\begin{array}{l}38(20.8 \%) \\
61(23.2 \%)\end{array}$ & $p=0.393$ \\
\hline
\end{tabular}


munity group (65.7\% female and 34.3\% male). The three groups did not differ statistically in sex $(\mathrm{p}=0.070)$. Individuals from the internal medicine group were older than the dermatology and community group individuals (mean age of $53.6 \mathrm{y}$ vs. $47.7 \mathrm{y}$ vs. $43.7 \mathrm{y} ; \mathrm{p}<0.001)$. The patients from the dermatology department had a higher education level (197 patients completed high school and 45 patients completed university). The dermatology group had the biggest percentage of individuals in all professional statuses $(\mathrm{p}<0.001)$. The patients from the dermatology group had more diagnosed skin diseases $(p<0.001)$. It is important to note that although patients from the dermatology group are followed for skin problems, 114 patients stated they had no skin disease.

The number of weekly baths did not differ in the three groups $(p=0.417) .125$ patients of the dermatology group, 44 patients of internal medicine group, and 45 individuals of the community group showered every day.

The dermatology group gave various reasons for showering less often. $30.5 \%$ of the dermatology group said that showering too often is bad for your skin, and $22.2 \%$ stated they do not shower more because of lack of time. In the community group, $60 \%$ of individuals stated that time constraints were their principal reason for not showering more often. In the three groups, shower gel was the most frequently used body cleanser. Twenty individuals from the internal medicine group, 25 from the dermatology group, and 9 from the community group stated they use bar soap ("lye soap") as body cleanser. Of the three groups, the dermatology group used bar soap more frequently $(p=0.003)$. In all groups showering was the most frequent type of bath. Almost every individual from the three groups said they had not reduced their number of baths in the last 2 years.

Hair hygiene did not differ between the three groups in terms of frequency $(p=0.227)$. The majority of individuals in the three groups (174 individuals from the dermatology group, 60 from the Internal medicine group, and 66 from the community group) washed their hair more than 3 or 4 times per week. The majority wash their hair at home and use over-the-counter shampoo and conditioner.

The dermatology and internal medicine groups washed their hands more frequently than the community group $(\mathrm{p}=0.028)$. Liquid soap was the most frequently used hand cleanser. Thirtyfive individuals from the dermatology group, 32 from the internal medicine group, and 11 from the community group stated they washed their hands with bar soap.

The majority of individuals from the three groups stated they use beauty products and there was no statistical difference between groups $(\mathrm{p}=0.393)$.

We analyzed each group of individuals separately and did not find significant differences in hygiene habits between sexes. Individuals younger than 65 years shower more frequently, and $60.5 \%$ of the dermatology patients that only shower once a week were older than $65(\mathrm{p}<0.001)$. Of the individuals that stated they only wash their hair once to twice a week, $47.2 \%$ of individuals belonged to the age group older than 65 . In the dermatology group and internal medicine group individuals younger than 65 years use beauty products more frequently $(\mathrm{p}<0.001)$.

\section{Discussion}

To our knowledge this is the first scientific study that describes and compares hygiene habits in three groups of individuals (a dermatology group, internal medicine group and community group).
We believe this study should be used as a starting point for characterization of hygiene habits in population groups with different geographic, cultural, and economic profiles. The publication of these studies will offer epidemiologic data about hygiene habits and ultimately establish practical recommendations in terms of body hygiene for our patients and the general population.

We are aware that our study has some limitations. Because there are no comparative scientific studies, we cannot conclude objectively if the hygiene habits of our population groups are more adequate than other groups. Our sample size is small and we did not estimate sample size previously. We used a non-random sampling technique because it was the most practical and accessible way of sampling our participants. We used opportunity sampling, and thus we are aware our data cannot be generalized to all dermatology or internal medicine or community populations. Due to difficulties in subject selection, the internal medicine and community groups were smaller than the dermatology group. We did not estimate sample size and made every effort to include the maximum number of subjects in each group.

Common knowledge frequently suggests that women have more adequate hygiene than men. Surprisingly, our study revealed no gender differences between the three groups in terms of hygiene habits. Although one French internet survey (3) stated that $70 \%$ of women and $60 \%$ of men do not shower every day, our study demonstrated that $50.2 \%$ of the dermatology group, $44.9 \%$ of the internal medicine group and $45.5 \%$ of the community group shower every day, and less than $18.4 \%$ of all individuals shower only once or twice a week. An English internet survey (4) declared that the most common reason given for showering so little was time constraints. In our study, $60 \%$ of internal medicine group individuals and $22.2 \%$ of the dermatology group also referred to time constraints as the reason for not showering more often. Interestingly, 30.5\% of the dermatology group stated that they do not shower more often because it is bad for your skin. Although some diseases may be aggravated by dehydration of the stratum corneum during frequent, hot, long-lasting baths, many other diseases may result from or be aggravated if there is inadequate hygiene. Our study identified the use of bar soap as a poor hygiene habit that should be discouraged. Bar soap (or "lye soap") is abrasive by promoting protein denaturation, has a high $\mathrm{pH}$ and should not be used for body/hair/handwashing. $20.4 \%$ and $32.7 \%$ of individuals from the internal medicine group, $10.0 \%$ and $14.1 \%$ from the dermatology group, and $9.1 \%$ and $11.1 \%$ from the community group used bar soap as body and hand cleanser, respectively. In an attempt to establish a correlation between the economic crisis and reduction in hygiene habits we asked: "Have you reduced your number of baths in the last 2 years?” Our study failed to corroborate this assumption and almost all individuals from the three groups had not changed their hygiene habits in the last 2 years.

It is commonly believed that, because women have longer hair, that they wash their hair less frequently than men. It is also believed that women have their hair washed more frequently at the hairdresser. Ours study demonstrated that there were no gender differences in terms of hair hygiene.

Although the dermatology and internal medicine groups washed their hands more frequently than the community group, all groups can be considered as having adequate hand hygiene. At least $60 \%$ of all individuals wash their hands more than 5 times per day and less than $6 \%$ stated that they washed their hands only once or twice a day. 
It is known that individuals that are professionally and socially active and practice sports might tend to shower more frequently. As expected, individuals older than 65 years were identified as showering and washing their hair less often. Although it is acceptable that with age and the resultant decrease in physical activity there may be a decrease in hygiene habits, it is also true that the skin barrier properties of the stratum corneum are modified with age. We consider that some individuals older than 65 years may not have the need to shower every day, but we believe that 1 to

\section{References}

1. Bhutani T, Peng D, Shin T, Lee H. Common sources of skin care education: a cross-sectional study. Int J Dermatol. 2009;48:506-12.

2. McLeod RP, Elias PM, Eichenfield LF, Fowler JF, Horowitz P. A lifetime of well skin care: practical recommendations for clinicians and patients. Semin Cutan Med Surg. 2013;32(Suppl 2):S28-9.

3. Ostermann O. Doit-on vraiment se laver tous les jours? [Internet]. Le Figaro Madame. c2002 - [cited 2015 Feb 24]. Available from: http://madame.lefigaro.fr/ beaute/faut-il-vraiment-se-laver-tous-les-jours-200215-94695. French.
2 showers a week may be insufficient, especially in the summer.

\section{Conclusion}

When we compare our results with the limited available data, we find that the surveyed population has better hygiene habits than those previously reported. Our study demonstrated a relatively large number of subjects that use bar soap ("lye soap"). We believe that hygiene habits should be discussed during office visits.

4. Four out of five women don't shower every day [Internet]. The Telegraph. c2015 - [cited 2015 Feb 22]. Available from: http://www.telegraph.co.uk/news/newstopics/howaboutthat/11427875/Four-out-of-five-women-dont-shower-everyday.html. 